\title{
Steroid management in giant cell arteritis
}

\author{
Colin C K Chan, Mark Paine, Justin O’Day
}

\begin{abstract}
Aim-Ocular involvement in giant cell arteritis (GCA) is an ophthalmic emergency which, if untreated, can progress to permanent blindness. There is little evidence in the literature to support current protocols for the acute treatment of GCA with steroids. The authors sought to review the effects of intravenous and oral steroids in GCA.
\end{abstract}

Methods-This retrospective study reviewed the records of 100 consecutive patients with biopsy proved giant cell arteritis. 73 patients with visual loss who were treated at the Royal Victorian Eye and Ear Hospital (RVEEH) and St Vincent's Hospital were included in the final series. The authors studied the management of the patients in the first week after presentation, analysing types of treatment, dose, effect on visual acuity, and complications.

Results-All the patients except one had visual loss due to anterior ischaemic optic neuropathy (AION). 17 patients $(23 \%)$ had bilateral eye involvement. Visual acuity improved in 21 of 73 patients $(29 \%)$ by a mean of two Snellen chart lines after commencement of steroids. There was an increased likelihood of improved vision in the group who had intravenous steroids $(40 \%)$ compared with those who received oral steroids (13\%). In all except four patients $(95 \%)$ vision remained stable at 1 month review.

Conclusions-Prompt treatment of GCA with steroids leads to improvement of visual acuity in a significant number of cases. Intravenous steroids may offer a greater prospect of improvement compared with oral steroids. A prospective trial comparing intravenous with oral steroids is needed to validate these findings and would not expose elderly patients to unacceptable risks.

(Br f Ophthalmol 2001;85:1061-1064)

Department of Neuro-Ophthalmology, Royal Victorian Eye and Ear Hospital, Melbourne, Australia C C K Chan

M Paine

J O'Day

Correspondence to: Dr Chan

chunkeng@yahoo.com

Accepted for publication 28 March 2001
Visual loss in giant cell arteritis (GCA) is an ophthalmic emergency. Anterior ischaemic optic neuropathy (AION), central retinal artery occlusion, ischaemic retinopathy and choroidopathy, and cranial nerve palsies are just some of the complications of GCA. Worse, the disease affects an elderly population of patients, people least able to adapt to a reduction in their vision. ${ }^{1}$ There is cumulative anecdotal experience supporting steroids, but there are few studies that support various dosage regimens or intravenous over oral steroids. We conducted a two centre retrospective study to review the effects of intravenous versus oral steroids in giant cell arteritis.

\section{Methods}

This retrospective study began with the review of 100 consecutive patients with biopsy proved giant cell arteritis treated at the Royal Victorian Eye and Ear Hospital (RVEEH) and St Vincent's Hospital (SVH), Melbourne, Australia. Initial presentation of these patients was between April 1988 to November 1998. Seventy three of the original 100 patients were included in the final numbers based on fulfilment of the following criteria: (1) treatment had to be initiated at RVEEH or SVH. Patients who did not fulfil this criterion had inadequate medical records for the purpose of the study; (2) visual loss on presentation. Visual loss meant either a decrease in visual acuity and/or the presence of a relative afferent pupillary defect. Diplopia was not interpreted as visual loss. Patients who presented with temporal headaches, jaw claudication or constitutional symptoms, but without visual loss were not included in the study; (3) a positive temporal artery biopsy; (4) adequate follow up with review at 1 week and 1 month after presentation.

The study looked retrospectively at management with steroids in the first week following presentation with visual acuity and side effects used as outcome measures.

ACUTE MANAGEMENT

All patients presenting to the RVEEH and SVH received treatment with steroids within 48 hours of onset of their visual symptoms. Patients were treated with either oral prednisolone or high dose intravenous methylprednisolone. A number of aspects of their initial management were looked at including: (1) treatment route, (2) dose and duration of initial steroid therapy, (3) major complications from use of steroids, (4) visual acuity at presentation, discharge, and 1 month review. To be classified as a major complication, the side effect had to require transfer out of the ophthalmology unit to a medical or surgical unit for further management. This did not include patients who experienced minor complications as a result of treatment-for example, anxiety and unstable diabetes. Details of visual acuity included whether visual loss was unilateral or bilateral. In cases that were bilateral, the visual acuity of the worse eye was used. Visual acuities that could not be converted to logmar such as counting fingers (CF) were categorised as one Snellen line above $1 / 60$, hand movements (HM) two lines, perception of light (PL) three lines, and no perception of light (NPL) to be four lines. 
Table 1 Patient characteristics

\begin{tabular}{|c|c|c|c|c|}
\hline Characteristic & Oral steroids & IV steroids & Analysis type & p Value \\
\hline Patients $(n=73)$ & 30 & 43 & & \\
\hline $\begin{array}{l}\text { Unilateral eye involvement } \\
(\mathrm{n}=56)(77 \%)\end{array}$ & 24 & 32 & & \\
\hline Bilateral $(n=17)(23 \%)$ & 6 & 11 & $\chi^{2}$ & 0.53 \\
\hline Right eye $(n=37)(51 \%)$ & 17 & 20 & $\chi^{2}$ & 0.05 \\
\hline Mean age (SD 7) & 73 & 76 & $t$ test & $<0.001$ \\
\hline Female $(n=49)(67 \%)$ & 18 & 31 & $\chi^{2}$ & 0.04 \\
\hline $\begin{array}{l}\text { Treatment dose (median) } \\
\text { (mg/day) }\end{array}$ & 75 & 1000 & & \\
\hline $\begin{array}{l}\text { Treatment within } 48 \text { hours of } \\
\text { symptoms }\end{array}$ & 30 & 43 & & \\
\hline \multicolumn{5}{|l|}{ VA on presentation } \\
\hline $6 / 12$ or better $(0.3)$ & 13 & 8 & $\chi^{2}$ & 0.35 \\
\hline $6 / 18$ to $6 / 36(0.5-0.8)$ & 5 & 4 & $\chi^{2}$ & 0.64 \\
\hline $6 / 60$ or worse & 12 & 31 & $\chi^{2}$ & 0.04 \\
\hline
\end{tabular}

Table 2 Visual outcomes

\begin{tabular}{lllll}
\hline Visual outcome & Oral steroids & IV steroids & Analysis & p Value \\
\hline VA improved $(\mathrm{n}=21)(29 \%)$ & $4(5 \%)$ & $17(23 \%)$ & $\chi^{2}$ & 0.01 \\
VA same $(\mathrm{n}=43)(59 \%)$ & $24(33 \%)$ & $19(26 \%)$ & $\chi^{2}$ & 0.04 \\
VA worse $(\mathrm{n}=9)(12 \%)$ & $2(3 \%)$ & $7(10 \%)$ & $\chi^{2}$ & 0.22 \\
Totals & 30 & 43 & & \\
Complications & 1 & 4 & $\chi^{2}$ & 0.32 \\
Lines improved & 1.5 & 2.3 & $t$ test & 0.85 \\
\hline
\end{tabular}

Patients were classified according to whether their visual acuity had improved, stayed the same, or become worse. Cases that progressed from unilateral to bilateral were included in the "visual acuity worse" group. For patients who were not admitted, visual acuity at discharge was taken to be the visual acuity recorded at 1 week review. The patients who were admitted stayed in hospital for 5-7 days. Ethical approval for this retrospective study was granted through the ethics committee of the RVEEH. Statistical analysis of the data was performed using $\chi^{2}$ statistic for proportions and Student's $t$ test for continuous data on a standard Microsoft Excel worksheet with a Prenhall statistics program.

\section{Results}

PATIENT CHARACTERISTICS (SEE TABLE 1)

The range of patient age was from 59 to 87 with a mean of 75 . There was a female to male preponderance of $2: 1$. Fifty six patients presented with unilateral visual loss and 17 with bilateral visual loss. Right eye involvement was twice as common as left. Visual loss was due to AION in all patients except one who had a central retinal artery occlusion.

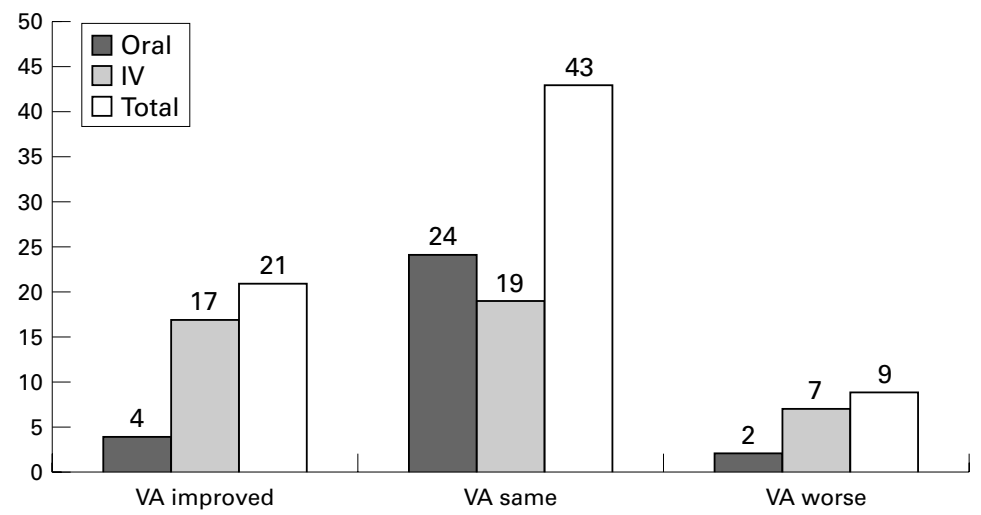

Figure 1 Change in visual acuity after treatment with intravenous or oral steroids.
INTRAVENOUS VERSUS ORAL STEROIDS

Forty three patients were treated with high dose intravenous (IV) methylprednisolone. Oral prednisolone was given in the remaining 30 patients. Median daily intravenous dose was $1000 \mathrm{mg}$. Many different steroid regimens were used. $1000 \mathrm{mg}$ intravenously daily for 3 days was used the most often. Other dose regimens used were $250 \mathrm{mg}$ intravenously four times daily, $250 \mathrm{mg}$ intravenously twice daily, $500 \mathrm{mg}$ intravenously twice daily, and $500 \mathrm{mg}$ intravenously daily. Intravenous steroids were given for a median of 3 days' duration (range $2-5$ days). Median inpatient stay was 6 days. In the 30 patients treated with oral prednisolone there was a wide range of doses from 50 to 100 $\mathrm{mg}$ daily and the median dose was $75 \mathrm{mg}$ daily.

The patients treated with intravenous steroids had a worse median visual acuity on presentation of counting fingers compared with $6 / 18$ for the oral group. Thirty one of 43 patients in the IV group $(72 \%)$ had an initial visual acuity of $6 / 60$ or worse compared with 12 of 30 in the oral group. This selection bias was found to be statistically significant $(p=0.04)$. There were also more patients with bilateral visual loss in the IV group, 11 of 17 or $65 \%$ but this was not a statistically significant bias $(\mathrm{p}=0.53)$.

Visual outcomes (based on comparison of visual acuity at presentation and discharge) after treatment with steroids are shown in Table 2 and Figure 1. Vision improved in 21 of 73 patients $(29 \%)$. Of these, $17(23 \%)$ had been treated with intravenous steroids while only four $(5 \%)$ had been treated with oral steroids. This difference was statistically significant $(p=0.01)$. The mean line improvement was two Snellen chart lines. Patients treated with intravenous steroids did not improve a statistically significant $(\mathrm{p}=0.85)$ greater number of Snellen lines (mean 2.3) compared with those treated with oral steroids (mean 1.5). However, there was a wide range of responses with one patient in the IV group improving eight lines from hand movements (HM) to 6/9. A further two cases treated with intravenous steroids improved five lines.

Visual acuity remained the same in 43 of 73 patients $(59 \%)$. Of these, $19(26 \%)$ were treated with intravenous steroids compared with the $24(33 \%)$ who were treated with oral steroids. Visual acuity became worse in nine of 73 patients $(12 \%)$. Of these, seven $(10 \%)$ had been treated with intravenous steroids while two $(3 \%)$ had received oral steroids. No statistical significance could be attached to this $(p=0.22)$. Four patients progressed to bilateral visual loss. Three of these had received intravenous steroids.

When different intravenous steroid regimens were compared, there was no appreciable difference between them in terms of visual outcome $(p=0.93)$. Likewise those patients who received higher doses of intravenous steroids did not have different visual outcomes from those who received lower doses $(p=0.66)$ (Table 3 and Fig 2).

Of those patients receiving intravenous steroids, four of $43(9.3 \%)$ experienced major 
Table 3 Using $15 \mathrm{mg} / \mathrm{kg} /$ day (1000 $\mathrm{mg} /$ day for a $70 \mathrm{~kg}$ person) as an arbitrary reference demonstrates that higher doses of intravenous steroids do not appear to be more effective in stabilising and restoring vision. ( $p$ value $=0.66$ by $\chi^{2}$ analysis)

\begin{tabular}{lccl}
\hline Steroid dose $(\mathrm{mg} / \mathrm{kg})$ & VA improved $(n=16)$ & VA same $(n=19)$ & VA worse $(n=8)$ \\
\hline Greater than $15(\mathrm{n}=16)$ & 6 & 6 & 4 \\
15 or less than $15(\mathrm{n}=27)$ & 10 & 13 & 4 \\
\hline
\end{tabular}

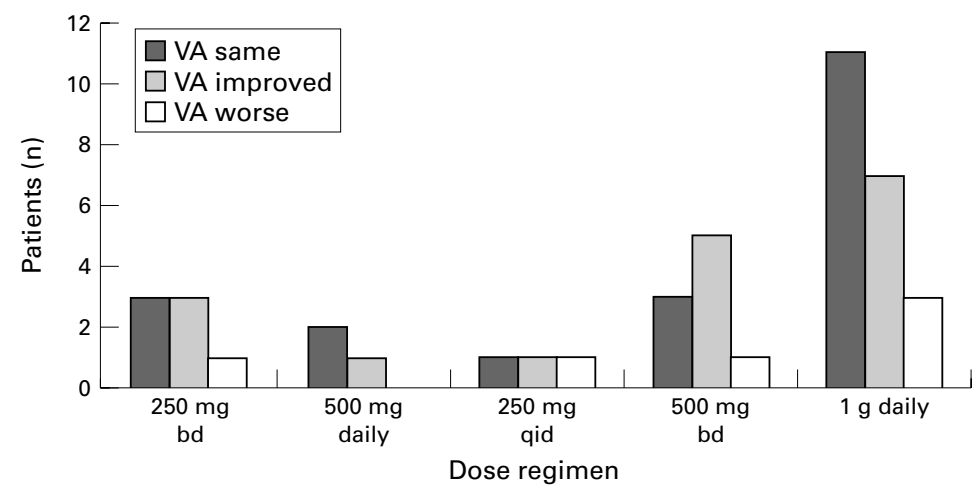

Figure 2 No trends are evident when comparing different intravenous steroid regimens as to which is more effective in treatment of GCA in terms of visual acuity outcome $(p=0.93)$

complications related to use of high dose steroids. Dividing the dose did not appear to affect the complication rate (two patients had divided doses, two did not). These included one case of unstable angina, one case of acute pulmonary oedema secondary to ischaemia, one case of an abdominus rectus sheath haematoma, and one case of uncontrolled hypertension. In addition, one woman treated with oral steroids developed an acute brain syndrome. No deaths resulted from the use of steroids.

Review of visual acuity at 1 month showed that all except four patients $(95 \%)$ continued to have vision equal to or better than at presentation. Of those patients in the visual acuity improved group treated with intravenous steroids, 13 of 17 patients $(76 \%)$ continued to have improved visual acuity at 1 month review compared with visual acuity at discharge (two patients were lost to follow up).

\section{Discussion}

Intravenous high dose steroids were first advocated as treatment more than 21 years ago after a single case report of improvement in vision after their use. ${ }^{2}$ The combination of further anecdotal reports of their efficacy and a few reports of the failure of oral steroids have led to the increasing use of high dose steroids. ${ }^{2-4}$ There is only a very modest amount of literature published to support the use of intravenous steroids with a few small retrospective trials and certainly no prospective trials. ${ }^{5-8}$ This void of evidence has been noted on several occasions in the literature by a number of authors. $^{9-12}$

There are three fundamental aims of treatment in ocular giant cell arteritis. These are prevention of further visual loss and involvement of the fellow eye, restoration of vision, and suppression of disease activity. ${ }^{72} 13$ Is there any evidence to suggest that steroids and, in particular, intravenous steroids fulfil any of these aims? The results of our study certainly suggest that prompt treatment with steroids, oral or intravenous, leads to an improvement in visual acuity in a significant number of patients. This improvement seems to be sustained at least to 1 month after presentation. The importance of early treatment is emphasised in a number of other studies. ${ }^{13-17}$

Furthermore, our results suggest that intravenous steroids may offer a greater prospect of vision restoration than oral steroids (17 of 21 compared with four of 21). Intravenous steroids may also improve vision by a greater amount of Snellen lines than oral steroids. We do, however, acknowledge the inherent selection bias in a retrospective study of this sort. Those patients who had poorer vision at presentation were more often treated with intravenous steroids than with oral. These patients probably had more labile disease and greater potential for recovery.

Further support for intravenous steroids can be found in another retrospective trial published by Liu et al who found that nine of 23 patients who had intravenous therapy (39\%) improved compared with five of 18 who had oral therapy $(28 \%) .^{5}$ Contrary findings can also be found in the literature. Gonzalez et al found intravenous steroids offered no advantage over oral steroids in a retrospective study of 69 patients with biopsy proved giant cell arteritis with vision improving in a total of eight patients. ${ }^{7}$ Another study cites five cases of progressive visual loss despite high dose intravenous steroids. ${ }^{6}$ The reliability of such data is questionable given the small numbers. Obviously in the face of conflicting evidence larger retrospective and prospective trials are needed.

However, a number of issues must be considered with the use of intravenous steroids such as the prevalence of side effects, dose, and the possibility of using high dose oral steroids as an alternative. Documented complications of methylprednisolone include sudden death, cardiac arrhythmias, infection, seizures, avascular necrosis of the femoral head, anaphylaxis, psychiatric disorders, hyperglycaemia, and gastrointestinal disturbances. ${ }^{516-18}$ Sudden death has been reported in at least 10 cases. However, the potential benefits of intravenous steroids probably outweigh the potential risks. Even one line improvement in vision has a huge impact on the ability of a patient to live an independent life. This applies especially in the elderly who may already have other impairments impacting upon their ability to perform activities of daily living. The above complications are not common and this is borne out by the major complication rate found in our study of four of $43(9.3 \%)$. Furthermore, no deaths occurred in our study as a result of the use of intravenous steroids. Oral steroids also can have side effects such as hyperglycaemia, psychiatric disturbances, hypertension, and hypokalaemia. ${ }^{5^{16}}$ One patient in our study developed an acute brain syndrome secondary to high dose oral steroids.

There currently is no consensus regarding the dose, regimen, and duration patients should be treated. In the literature, dose recommendations vary from a single $500 \mathrm{mg}$ 
dose to $1 \mathrm{~g}$ daily for durations of between 1 and 5 days. ${ }^{19-22}$ It appears from our data that visual outcome is not affected by the dose of intravenous steroid nor the regimen. Not dividing the dose of steroid also does not seem to cause complications. Admittedly, the numbers in our study are not sufficient to be conclusive. In addition, as our study was retrospective, it was not possible to stratify or randomise the treatment regimens. This is an issue that definitely needs further elucidation with prospective trials.

The issue of whether high dose oral steroids (more than $100 \mathrm{mg}$ /day) would be as effective as intravenous steroids also needs to be answered. Intravenous steroids are favoured for a number of reasons including the delivery of drug directly to the site of disease - that is, the optic nerve, bypass of variable gastrointestinal absorption and patient inability to swallow the appropriate number of tablets. ${ }^{23}{ }^{24}$ However, others advocate high dose oral steroids because of theoretically better steady state levels, avoidance of intravenous steroid related complications, and ease of delivery. ${ }^{142526}$ In some centres, patients are initially given both oral and intravenous steroids for more severe disease. ${ }^{27}$

\section{Conclusion}

There is paucity of evidence on which to support our current treatment of GCA. While limited by its retrospective nature, this study adds significant weight to the argument that steroids can improve vision and that intravenous steroids may be superior to oral steroids. The need for a prospective trial to validate these findings is as great as ever and the risks would not be unacceptable.

We thank Daniel McCarty, $\mathrm{PhD}$, for his advice on statistical analysis of data

1 Bengtsson BA, Malmvall BE. The epidemiology of giant cell arteritis including polymyalgia rheumatica. Arthritis Rheum 1981;24:899-904

2 Postel EA, Pollock SC. Recovery of vision in a 47 year old man with fulminant giant cell arteritis. $f$ Clin Neuroophthalmol 1993;13:262-70.
3 Hugod C, Scheibel M. Temporal arteritis-progressive affection of vision during high level corticosteroid therapy. A case report. Acta Med Scand 1979;205:445-6.

4 Calamia KT, Hunder GG. Giant cell arteritis presenting as fever of undetermined origin. Arthritis Rheum 1981;24: 1414-8.

5 Liu GT, Glaser JS, Schatz NJ, et al. Visual morbidity in giant cell arteritis. Clinical characteristics and prognosis for vision. Ophthalmology 1994;101:1779-85.

6 Cornblath WT, Eggenberger ER. Progressive visual loss from giant cell artreitis despite high dose intravenous from giant cell artreitis despite high dose intrave

7 Gonzalez-Gay MA, Blanco R, Rodriguez-Valverde V, et al. Gonzalez-Gay MA, Blanco R, Rodriguez-Valverde $V$, et al.
Permanent visual loss and cerebrovascular accidents in giant cell arteritis: predictors and response to treatment Arthritis Rheum 1998;41:1497-504.

8 Hwang JM, Girkin CA, Perry JD, et al. Bilateral ocular ischaemic syndrome secondary to giant cell arteritis progressing despite corticosteroid treatment. Am $\mathcal{f} O p h$ thalmol 1999;127:102-4.

9 Hayreh SS. Ophthalmic features of giant cell arteritis. Bailliere's Clin Rheumatol 1991;5:431-59.

10 Clearkin LG. IV steroids for central retinal artery occlusion in giant-cell arteritis Ophthalmology 1992;99:1482-83.

11 Ferris J, Lamb R. Polymyalgia rheumatica and giant cell arteritis. BMF 1995;311:455

12 Diamond JP. IV steroid treatment of giant cell arteritis [letter]. Ophthalmology 1992;100:291-2.

13 Cullen JF. Occult temporal arteritis. Trans Ophthalmol Soc UK 1963;83:725-36

14 Hayreh SS. Anterior ischaemic optic neuropathy. Differentiation of arteritic from non arteritic type and its management. Eye 1990;4:25-41

15 Myles AB. Prognosis of polymyalgia rheumatica and giant cell arteritis. Bailliere's Clin Rheumatol 1991;5:493-503

16 Bengtsson BA, Malmvall BE. The epidemiology of giant cell arteritis including polymyalgia rheumatica. Arthritis Rheum arteritis including

17 Anderson R, Malmvall BE, Bengtsson BA. Long term corticosteroid treatment in giant cell arteritis. Acta Med Scand 1986;220:465-9.

8 Graham E, Holland A, Avery A, et al. Prognosis in giant cell arteritis. Br Med F Clin Res Ed 1981;282:269-71.

19 Paice EW. Giant cell arteritis: difficult decisions in diagnosis, investigation and treatment. Postgrad Med $\mathcal{F}$ 1989;65:743-747.

20 Hunder GG. Giant cell arteritis. Rheum Dis Clin North Am 1990;16:339-409.

21 Hunder GG. Polymyalgia rheumatica and temporal arteritis. Pr Rheum Dis 1988 .

22 Whitfield F, Nielsen HS, Frederiksen JL, et al. Temporal arteritis. Br f Ophthalmol 1963;47:555-66.

23 Wray SH. Optic neuritis: guidelines. Curr Opin Neurol 1995; 8:72-6.

24 Selleberg AGW, Bateman M, Trevor Cooke W, et al. A randomized, controlled trial of oral high dose methylprednisolone in acute optic neuritis. NEURA 1999;52:147984.

25 Gambertoglio JG, Amend WJ, Benet LZ. Pharmacokinetics and bioavailability of prednisolone and prednisolone in healthy volunteers and patients: a review. $¥$ Pharmacokinet Biopharm 1980;8:1-52.

26 Wind E. Temporal arteritis. Aggressive treatment prevents visual complications. Postgrad Med f 1992;91:337-8, $341-2$.

27 Hayreh SS. Podhajsky PA, Zimmerman B. Ocular manifestations of giant cell arteritis. Am F Ophthalmol 1998;125: 509-20. 